\title{
Autoantibodies to oxidised low density lipoproteins in IDDM are inversely related to metabolic control and microvascular complications
}

\author{
A. Festa ${ }^{1}$, H.P. Kopp ${ }^{1}$, G. Schernthaner ${ }^{1}$, E.J. Menzel $^{2}$ \\ ${ }^{1}$ Department of Medicine 1, Rudolfstiftung Hospital, Vienna, Austria \\ ${ }^{2}$ Institute of Immunology, University of Vienna, Austria
}

\begin{abstract}
Summary Diabetes mellitus is associated with an increased risk of atherosclerosis. The oxidation of lowdensity lipoproteins (LDL) is considered a key event in the initiation of atherosclerosis. To investigate LDL oxidation in vivo we measured autoantibodies to oxidised LDL (oxLDL) in 94 patients with insulindependent diabetes mellitus (IDDM), compared to 27 age-matched, healthy control subjects. Patients and control subjects were screened for autoantibodies using a solid phase ELISA, comparing the binding to oxLDL with that to native LDL (nLDL). In patients with IDDM the oxLDL/nLDL antibody ratio was significantly higher than in control subjects (means \pm SEM: $2.24 \pm 0.26$ vs $1.17 \pm 0.17, p<0.03$ ). Antibodynegative patients had a longer diabetes duration $(13.5 \pm 1.3$ vs $9.1 \pm 1.1$ years, $p<0.01)$ and higher actual and mean $\mathrm{HbA}_{1 \mathrm{c}}$ levels compared to antibody-
\end{abstract}

positive patients $(8.8 \pm 0.2$ vs $7.9 \pm 0.2 \%, p<0.005$ and $8.3 \pm 0.2$ vs $7.7 \pm 0.2 \%, p<0.03$; respectively). In patients with a high microangiopathy score, the antibody ratio was lower than in patients without complications $(1.04 \pm 0.10$ vs $2.40 \pm 0.29, p<0.01)$. OxLDL specific immune complexes were found exclusively in antibody-negative as compared to antibody-positive patients $(18.3$ vs $0 \% ; p<0.01)$. Our data demonstrate an inverse relationship between free oxLDL antibodies and the severity of the disease. This apparent paradox can be explained in part by our demonstration of oxLDL immune complexes, masking free antibodies. [Diabetologia (1998) 41: 350-356]

Keywords Autoantibodies, oxidised LDL, diabetic late complications, atherosclerosis, immune complex, insulin-dependent diabetes mellitus.
Diabetes mellitus has been identified as an important risk factor in the development of atherosclerosis, independent of other risk factors, such as hypertension and hyperlipidaemia [1]. The reason for the accelerated atherosclerosis is still a matter of debate, with various mechanisms being discussed, such as disor-

Received: 18 June 1997 and in final revised form: 30 September 1997

Corresponding author: Prof. G. Schernthaner, Department of Medicine 1, Rudolfstiftung Hospital, Juchgasse 25, A-1030 Vienna, Austria

Abbreviations: oxLDL, Oxidised LDL; nLDL, native LDL; oLAb, autoantibodies directed against oxidised LDL; MDA, malondialdehyde; IC, immune complex; Ig, immunoglobulin; HSA, human serum albumin; PBS, phosphate-buffered saline; IDDM, insulin-dependent diabetes mellitus; NIDDM, non-insulin- dependent diabetes mellitus. ders in coagulation and fibrinolysis [2], hyperinsulinaemia [3], the formation of advanced glycation end products by non-enzymatic modification of proteins [4] and the glycation and/or oxidation of lipoproteins [5]. Recently, considerable attention has been drawn to the latter mechanism [6], with clear evidence that the oxidation of LDL - considered a key event in the initiation and progression of atherosclerosis - actually occurs in vivo [7]. According to the responseto-injury hypothesis, oxidatively modified LDL leads to an increased adherence of monocytes/macrophages, which are transformed into foam cells because of lipid accumulation and, with T cells and smooth muscle cells, finally form fatty streaks [8]. In addition to its chemotactic properties for circulating monocytes, oxLDL can be directly cytotoxic, it inhibits the motility of tissue macrophages, it is capable of altering gene expression, and it can adversely affect coagula- 
tion pathways as well as vasomotor properties of coronary arteries [9]. The comparison of the oxidative modification of LDL in different individuals relies on two methods: the assessment of the susceptibility of isolated LDL to oxidation in vitro [10], and the quantitation of oxLDL in vivo. OxLDL has been demonstrated in peripheral blood [11]. However, given the high antioxidant capacity of human plasma, it seems probable that LDL in the subendothelial space is more prone to oxidative modification than circulating LDL. The oxidative modification of LDL that occurs in vivo generates antigenic epitopes within LDL that may trigger an autoimmune response, even in healthy persons [12].

High titres of autoantibodies against oxLDL (oLAb) have been detected in the plasma of patients with essential hypertension [13], non-insulin-dependent diabetes mellitus (NIDDM) [14], coronary heart disease [12], carotid atherosclerosis [15] and chronic renal failure [16]. In experimental mouse models of atherosclerosis high titres of autoantibodies against MDA-LDL were demonstrated as well as oxidationspecific epitopes within atherosclerotic lesions [17]. Detection of oLAb has therefore been proposed as an indirect marker of LDL oxidation actually occurring in vivo $[15,16]$. Less information exists about the significance of LDL-containing immune complexes (IC) in atherogenesis. However, LDL-IC in vitro not only are even more effective than modified lipoproteins in inducing the transformation of human macrophages into foam cells [18], but are also able to activate macrophages with subsequent induction of the release of free oxygen radicals as well as inflammatory cytokines, such as interleukin $1-\beta$ and tumour necrosis factor alpha (TNF- $\alpha)[19,20]$.

Patients with diabetes are exposed to increased auto-oxidative glycation reactions [21] as a consequence of the combined action of increased oxidative stress and hyperglycaemia. Products of free radical reactions, such as peroxidative modifications of unsaturated lipids, were found to be elevated in diabetic patients with signs of microangiopathy [22]. Thus, LDL is progressively altered by oxidative modification in diabetic patients [23]. Also, it was demonstrated that LDL-glycation is enhanced in diabetes [24, 25 ] and that it correlates with parameters of metabolic control [26]. Moreover, in vitro data suggest an increased susceptibility of LDL to oxidation in insulindependent diabetes (IDDM) [27] and NIDDM [28, 29]. In plasma of patients with NIDDM high titres of $\mathrm{oLAb}$ were found [14]. However, data dealing with LDL-oxidation in vivo in patients with IDDM are scarce [30]. In this study we measured autoantibodies directed against oxidatively modified LDL as well as oxLDL containing immune complexes in 94 consecutive patients with IDDM without clinical evidence of macrovascular disease. The aim of our study was therefore to assess the oLAb status in patients in a potentially preclinical atherosclerotic state. In addition, we analysed the relationship between oLAb and metabolic control as well as microvascular complications, such as retinopathy and incipient nephropathy.

\section{Materials and methods}

Study subjects. Ninety-four patients with IDDM, as defined by the National Diabetes Data Group [31], and 27 healthy control subjects were recruited from the patients and the staff of the Department of Medicine 1, Rudolfstiftung Hospital, Vienna. Demographic and metabolic data of patients and control subjects are summarized in Table 1 . The study was performed in accordance with the principles of the Declaration of Helsinki, 1979. Patients with clinically overt macrovascular disease (history of previous myocardial infarction, angina pectoris, peripheral obstructive disease, brain transitory ischaemic attack or stroke; ischaemic ECG changes; overt nephropathy) were excluded from the study. Information about microvascular disease was available for 83 patients for retinopathy and 94 for incipient nephropathy (albuminuria). Data on retinopathy was obtained by direct ophthalmoscopy with mydriasis. A score for microvascular complications was defined by giving nonproliferative retinopathy and microalbuminuria 1 point each and proliferative retinopathy and macroalbuminuria 2 points each.

Clinical laboratory measurements. Routine blood chemistry was determined by an American Monitor Parallel Analyser (Richmond, Va., USA). $\mathrm{HbA}_{1 \mathrm{c}}$ was measured using an HPLC technique (Biorad; Diamat, Hercules, Calif.; normal range 4.5-6\%). In 91 patients at least $2 \mathrm{HbA}_{1 \mathrm{c}}$ measurements (range: 2-27) were performed at least for a period of 6 months (range: 6-84). The mean value of the repeated $\mathrm{HbA}_{1 \mathrm{c}}$ measurements as well as the actual $\mathrm{HbA}_{1 \mathrm{c}}$ value were considered for analysis. Urinary albumin excretion rate (UAER) was measured by an immunoturbidimetric test (Tina-quant; Boehringer Mannheim, Mannheim, Germany). Microalbuminuria was defined as UAER of $30-300 \mathrm{mg} / 24 \mathrm{~h}$ and macroalbuminuria as an UAER of over $300 \mathrm{mg} / 24 \mathrm{~h}$ in at least 2 of 3 consecutive measurements. All patients had serum creatinine values within the normal range.

Detection of autoantibodies against oxidised LDL (oLAb). Patients and control subjects were screened for oLAb using a solid phase ELISA. Wells were coated either with oxLDL or with native LDL. LDL was isolated from blood of healthy individuals by sequential ultracentrifugation. Oxidation of LDL (kindly donated by Professor H. Esterbauer, Graz, Austria) was performed with $5 \mu \mathrm{mol} / \mathrm{l} \mathrm{Cu}^{++}$. Plastic wells were coated with a solution of nLDL or oxLDL $(25 \mu \mathrm{g} / \mathrm{ml})$ in $0.15 \mathrm{~mol} / \mathrm{l}$ carbonate buffer, $\mathrm{pH}$ 9.6. The wells were incubated for $24 \mathrm{~h}$ at $4{ }^{\circ} \mathrm{C}$. After removal of coating solution and washing, the wells were incubated for $2 \mathrm{~h}$ at room temperature with blocking buffer ( $1 \%$ human serum albumin (HSA) in phosphate buffered saline (PBS), $\mathrm{pH}$ 7.4). Dilution of sera was 1:50 using PBS, pH 7.4, $1 \%$ HSA. As a second antibody, antihuman Ig from rabbits was used in peroxidase-labelled form (1:1000). As chromogenic substrate 2,2'-azino-bis (3ethylbenz-thiazoline-6-sulfonic acid) (ABTS) was used. Since some sera showed non-specific binding of Ig to the oxLDL coated solid phase, we compared binding of oxLDL with that obtained in nLDL wells. Thus, antibody titres are ex- 
Table 1. Study populations

\begin{tabular}{lrrl}
\hline & \multicolumn{1}{c}{ Patients } & \multicolumn{1}{c}{ Controls } & $p$ value \\
\hline$n$ (male/female) & $94(43 / 51)$ & $27(15 / 12)$ & \\
Age (years) & $32.0 \pm 1.0$ & $30.9 \pm 1.7$ & NS \\
HbA $_{1 \mathrm{c}}(\%)$ & $8.5 \pm 0.2$ & $5.1 \pm 0.1$ & $<0.0001$ \\
Mean-HbA $_{1 \mathrm{c}}{ }^{\mathrm{a}}(\%)$ & $8.1 \pm 0.1$ & & \\
Disease-duration (years) & $11.9 \pm 0.9$ & & \\
Total cholesterol (mmol/1) & $5.3 \pm 0.1$ & $4.8 \pm 0.2$ & $<0.03$ \\
LDL-cholesterol (mmol/l) & $3.2 \pm 0.1$ & $3.1 \pm 0.2$ & $\mathrm{NS}$ \\
HDL-cholesterol (mmol/l) & $1.5 \pm 0.1$ & $1.2 \pm 0.1$ & $<0.001$ \\
Triglycerides (mmol/l) & $1.23 \pm 0.1$ & $1.24 \pm 0.1$ & $\mathrm{NS}$ \\
\hline
\end{tabular}

Data are expressed as mean \pm SEM

${ }^{a}$ Mean value of repeated measurements

Table 2. Demographic and metabolic data of oxLDL-antibody positive compared to negative patients

\begin{tabular}{|c|c|c|c|}
\hline \multicolumn{4}{|l|}{$\overline{\mathrm{oxLDL} / \mathrm{nLDL}}$} \\
\hline antibody ratio & $\begin{array}{l}\text { Positive } \\
(>1.5)\end{array}$ & $\begin{array}{l}\text { Negative } \\
(\leq 1.5)\end{array}$ & $p$ value \\
\hline$\overline{n(\text { male/female })}$ & $34(14 / 20)$ & $60(29 / 31)$ & \\
\hline Age (years) & $27.8 \pm 1.2$ & $34.3 \pm 1.3$ & $<0.001$ \\
\hline Actual $\mathrm{HbA}_{1 \mathrm{c}}(\%)$ & $7.9 \pm 0.2$ & $8.8 \pm 0.2$ & $<0.005$ \\
\hline Mean $\mathrm{HbA}_{1 \mathrm{c}}^{\mathrm{a}}(\%)$ & $7.7 \pm 0.2$ & $8.3 \pm 0.2$ & $<0.03$ \\
\hline Diabetes duration (years) & $9.1 \pm 1.1$ & $13.5 \pm 1.3$ & $<0.01$ \\
\hline Total cholesterol (mmol/l) & $5.2 \pm 0.2$ & $5.4 \pm 0.2$ & NS \\
\hline HDL-cholesterol (mmol/1) & $1.6 \pm 0.1$ & $1.5 \pm 0.1$ & NS \\
\hline LDL-cholesterol (mmol/l) & $3.1 \pm 0.2$ & $3.3 \pm 0.2$ & NS \\
\hline \multicolumn{4}{|l|}{ Microangiopathy score $(n)^{\mathrm{b}}$} \\
\hline 0 & 29 & 42 & \\
\hline 1 & 5 & 7 & \\
\hline$>1$ & 0 & 11 & \\
\hline
\end{tabular}

Data are expressed as mean \pm SEM

${ }^{a}$ Mean value of repeated measurements

${ }^{\mathrm{b}}$ Chi-square for microangiopathy score: $p<0.03$

pressed as the ratio between the photometric readings of antioxLDL and anti-nLDL. The ELISA result was defined as positive if the binding ratio oxLDL/nLDL exceeded the mean value of control subjects +2 SEM (1.5). To prove the specificity of oLAb we performed inhibition experiments using oxLDL or nLDL as inhibitors. Sera were diluted 1:50 using PBS, pH 7.4, $1 \% \mathrm{HSA}$ and incubated at $37^{\circ} \mathrm{C}$ for $60 \mathrm{~min}$ and $4{ }^{\circ} \mathrm{C}$ for $16 \mathrm{~h}$ with $200 \mu \mathrm{g} / \mathrm{ml}$ oxLDL, nLDL or without inhibitor in the presence of $0.2 \mathrm{mmol} / \mathrm{l}$ EDTA. These samples were then analysed for oLAb as described above.

Preparation of oxidised LDL. Prior to oxidation, LDL samples were dialysed overnight against PBS and then incubated with $5 \mu \mathrm{mol} / 1 \mathrm{Cu}^{++}$for $24 \mathrm{~h}$ at $37^{\circ} \mathrm{C}$. Oxidation was stopped by addition of $20 \mu \mathrm{l} 0.1 \mathrm{~mol} / \mathrm{l}$ EDTA per ml LDL solution, followed by dialysis against PBS containing $0.2 \mathrm{mmol} / \mathrm{l}$ EDTA at $4{ }^{\circ} \mathrm{C}$ for $24 \mathrm{~h}$. The degree of LDL oxidation was verified by the following criteria: content of dienes and MDA equivalents, electrophoretic shift and apolipoprotein B breakdown. Diene concentration was determined as described by Dimitriadis et al. [32], giving a value of $400 \mathrm{nmol} \cdot \mathrm{l}^{-1} \cdot \mathrm{mg}^{-1} \mathrm{LDL}$. The thiobarbituric acid reactive substances (TBARS) method was performed as described by us in a previous paper [33], resulting in 25 nmol malondialdehyde (MDA) equivalents per mg LDL. The electrophoretic mobility of native and oxidized LDL was compared by agarose gel electrophoresis at $\mathrm{pH} 8.6$ in $60 \mathrm{mmol} / \mathrm{l}$ barbital buffer $(60 \mathrm{~V}, 30 \mathrm{~mA}, 1 \mathrm{~h})$ using the Lipidophor cham- ber (Immuno AG, Vienna, Austria). After fixation, the separated bands were stained using Amido Black 10 B (Sigma, St. Louis, Mo., USA). The electrophoretic shift was expressed as relative electrophoretic mobility, which was 1.9 for oxLDL. The oxidative degradation of apolipoprotein B was determined as described by us [33].

Detection of circulating immune complexes. Circulating ICs were quantitated using a commercial assay for $\mathrm{C} 1 \mathrm{q}$ binding immune complexes (Quidel, San Diego, Calif., USA). To exclude interference by anti-immunoglobulin antibodies with the IC assay we determined the concentration of IgA-, IgGand IgM-rheumatoid factors using an ELISA method, showing the absence of anti-immunoglobulin antibodies in all our subjects.

Detection of oxLDL immune complexes (ox LDL-IC). We developed a solid phase ELISA for circulating oxLDL-IC using an immunochemical bridge for immobilising polyclonal antibodies directed against oxLDL. NUNC maxisorp 96 well plates (Nunc, Roskilde, Denmark) were coated with goat anti-rabbit IgG-Fc (Dianova, Hamburg, Germany), the "bridging antibody", diluted 1:50 with PBS containing $0.4 \%$ bovine serum albumin (BSA) and $0.02 \%$ sodium azide (PBSBSA). Coating was done by incubation for $30 \mathrm{~min}$ at $37^{\circ} \mathrm{C}$ and $40 \mathrm{~h}$ at $4{ }^{\circ} \mathrm{C}$. After washing with PBS- $0.1 \%$ Tween anti-oxLDL serum from rabbit (Elitec, Vienna, Austria), absorbed with nLDL to eliminate anti-LDL specificity, was added at a dilution of 1:100, which corresponds to the maximal binding capacity of these antisera for oxLDL. This was verified in previous titration studies using oxLDL-coated wells as solid phase. Incubation was as described for the bridging antibody. 1:20 diluted sera were incubated with the solid phase for $2 \mathrm{~h}$ at room temperature, peroxidase-labelled anti-human $\mathrm{IgG}$ (Amersham, Amersham, UK), diluted 1:1000 with PBS-1\% BSA, was added after thorough washing, incubated for $1 \mathrm{~h}$ at room temperature and peroxidase activity was determined using ABTS as substrate. OxLDL-IC positivity was defined as a value exceeding the mean value of non-diabetic control subjects +3 SD. This assay system does not detect general IC; i.e. non-oxLDL-IC, as verified by testing sera which were highly positive in the commercial IC-ELISA.

Assessement of GAD autoantibodies. GAD 65 antibodies were determined with a commercial ELISA (Diaplets anti-GAD; Boehringer Mannheim) using streptavidin-coated microtitre plates. Results were defined as positive at an antibody concentration of greater than $32 \mathrm{ng} / \mathrm{ml}$.

Statistical analysis. Analysis was performed using SAS statistical software. Results are given as mean values \pm SEM. Differences between groups were calculated by two tailed Student's $t$-test and chi-square. Correlation analysis was performed using Kendall's correlation coefficient. $p<0.05$ was considered statistically significant.

\section{Results}

Patients with IDDM showed a higher oxLDL/nLDL antibody ratio compared to age-matched non-diabetic control subjects $(2.24 \pm 0.26$ vs $1.17 \pm 0.17 ; p<$ $0.03)$, while no difference was detected with respect to anti-nLDL antibody titres (OD: $0.240 \pm 0.03$ vs $0.279 \pm 0.06$; NS). Absolute anti-oxLDL antibody ti- 


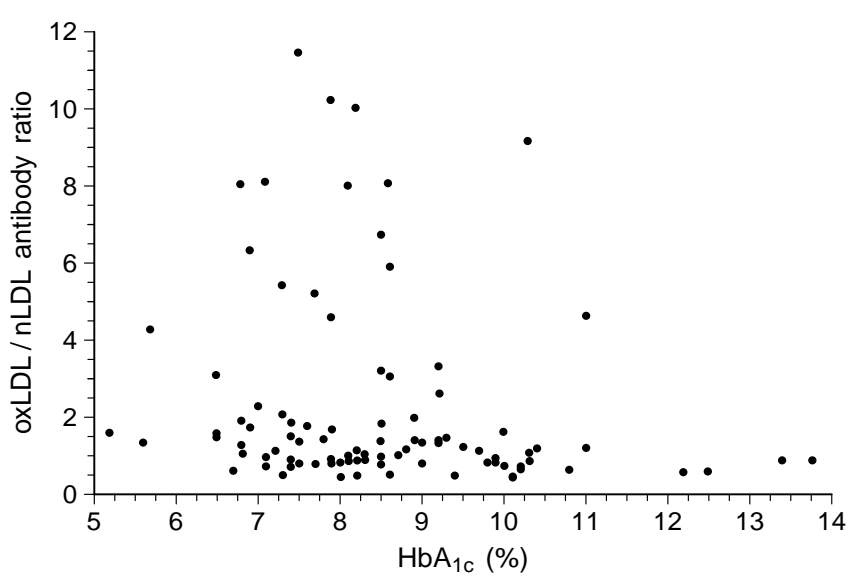

Fig. 1. Correlation of oxLDL/nLDL antibody ratio with $\mathrm{HbA}_{1 \mathrm{c}}$ in patients with IDDM $(n=94) ; r=-0.19, p<0.01$

Table 3. Clinical data and oxLDL-antibody status according to the microangiopathy score

\begin{tabular}{llll}
\hline Score & $0-1$ & $2-4$ & $p$ value \\
\hline$n$ & 83 & 11 & \\
Age (years) & $31.3 \pm 1.1$ & $37.2 \pm 2.9$ & $<0.04$ \\
Actual HbA $_{1 \mathrm{c}}(\%)$ & $8.4 \pm 0.2$ & $8.8 \pm 0.5$ & NS \\
${\text { Mean } \mathrm{HbA}_{1 \mathrm{c}}{ }^{\mathrm{a}}(\%)}^{\text {Diabetes duration }}$ & $8.0 \pm 1.4$ & $8.7 \pm 1.0$ & $<0.03$ \\
$\begin{array}{l}\text { (years) } \\
\text { oxLDL/nLDL }\end{array}$ & $10.7 \pm 0.9$ & $21.5 \pm 1.8$ & $<0.0001$ \\
Ratio & $2.40 \pm 0.29$ & $1.04 \pm 0.10$ & $<0.01$ \\
\hline
\end{tabular}

Data are expressed as mean \pm SEM

${ }^{a}$ Mean value of repeated measurements

tres were $0.449 \pm 0.06$ for patients and $0.252 \pm 0.05$ for control subjects $(p<0.05)$. Forty-five patients $(48 \%)$ revealed antibodies against oxLDL (oxLDL/nLDL ratio over 1.5 or were positive for oxLDL-IC) compared to $n=5(19 \%)$ of the control subjects $(p<$ 0.01).

Patients with a positive oxLDL/nLDL antibody ratio $(>1.5)$ had a shorter duration of diabetes $(9.1 \pm 1.1$ vs $13.5 \pm 1.3$ years; $p<0.01)$, lower actual as well as mean $\mathrm{HbA}_{1 \mathrm{c}}$ levels $(7.9 \pm 0.2$ vs $8.8 \pm 0.2 \% ; p<0.005$ and $7.7 \pm 0.2$ vs $8.3 \pm 0.2 \%$; $p<0.03$, respectively) and younger age (27.8 $\pm 1.2 \mathrm{vs}$ $34.3 \pm 1.3 ; p<0.001)$ as compared to antibody-negative patients. No significant difference could be detected with respect to sex and serum lipids (Table 2). OLAb were inversely related to metabolic control. In patients with an actual $\mathrm{HbA}_{1 \mathrm{c}} 9 \%$ or lower $(n=67)$ oxLDL antibody ratios were higher than in patients with an actual $\mathrm{HbA}_{1 \mathrm{c}}$ over $9 \%(n=27): 2.53 \pm 0.33$ vs $1.52 \pm 0.34 ; p<0.02$. The prevalence of oxLDL antibody positivity showed a continuous decline in patients with good $\left(\mathrm{HbA}_{1 \mathrm{c}}<7 \%\right)$ vs mean $\left(\mathrm{HbA}_{1 \mathrm{c}} 7-\right.$ $9 \%)$ vs poor $\left(\mathrm{HbA}_{1 \mathrm{c}}>9 \%\right)$ metabolic control (percentage of antibody-positive patients: 57.1 vs 39.6 vs $18.5 \%, p<0.05)$. Actual $\mathrm{HbA}_{1 \mathrm{c}}$ was inversely related to the oxLDL/nLDL antibody ratio $(r=-0.19$, $p<0.01$; Fig. 1 ).

The oxLDL antibody status was also inversely related to microvascular complications: in patients with a low microangiopathy score $(<2)$ the oxLDL antibody ratio was higher than in patients with a score of $\geq 2(2.40 \pm 0.29$ vs $1.04 \pm 0.10 ; p<0.01$; Table 3). Microangiopathy was found more frequently in oLAb negative patients: 42 patients had a score of $0, n=7$ had a score of 1 and $n=11$ had a score over 1 vs $n=29$ (score 0 ), $n=5$ (score 1 ) and $n=0$ (score $>1)$ in oLAb positive patients $(p<0.03$; Table 2 ). In patients, the oxLDL antibody ratio was inversely correlated with age $(r=-0.17 ; p<0.02$; Fig. 2). In the entire study population (patients and control subjects) the oxLDL antibody ratio correlated with HDL-cholesterol $(r=0.17, p<0.02)$ and inversely with age $(r=-0.14 ; p<0.03)$.

In addition, the specificity of oLAb was established by competitive assays as described under methods. We studied 30 patients with a positive oxLDL antibody status. The degree of inhibition observed with oxLDL as inhibitor was $48.9 \pm 6.4$ vs $19.3 \pm 2.7 \%$ using nLDL as inhibitor $(p<0.01)$. These results indicate a specific inhibition of oLAb by the antigen.

To clarify whether oLAb are masked in vivo by IC formation we determined circulating IC and IC containing oxLDL as antigen. Circulating C1q-binding IC were found in 4 patients with a positive oLAb ratio, in 10 antibody-negative patients and in none of the control subjects. None of the 34 antibody-positive patients was positive for oxLDL-IC compared to 11 among antibody-negative patients ( 0 vs $18.3 \%$, $p<0.01)$. The majority of oxLDL-IC positive patients (8/11) also demonstrated C1 q positive IC. The ox$\mathrm{LDL} / \mathrm{nLDL}$ antibody ratio was inversely correlated with oxLDL-IC ( $r=-0.31, p<0.0001$; Fig. 3$)$.

The prevalence of GAD antibody positivity was $30 \%$. There was no significant relationship between GAD antibody status and oxLDL antibody status (data not shown).

\section{Discussion}

Our data show that sera of patients with IDDM contain antibodies to oxidised LDL to a much higher extent than age-matched healthy individuals. The inverse age dependency of oLAb found in our IDDM population reflects a similar correlation in normal individuals [34] and might be explained by an increased binding of the antibodies to subclinical atherosclerosis lesions and/or by the regression of autoantibody production with increasing age or disease duration. To our knowledge, this is the first study assaying $\mathrm{oLAb}$ in free and immune complex-bound form in patients with IDDM. The specificity of the antibodies 


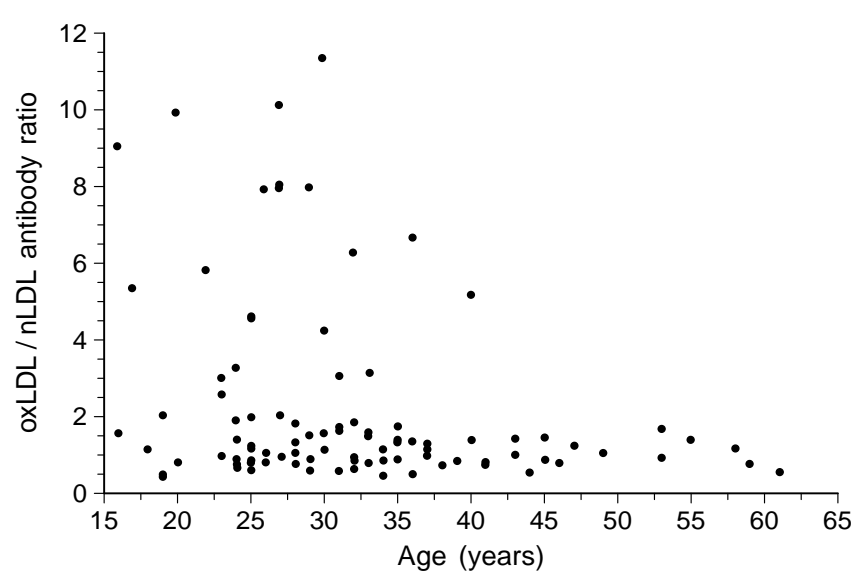

Fig. 2. Correlation of oxLDL/nLDL antibody ratio with age in patients with $\operatorname{IDDM}(n=94) ; r=-0.17, p<0.02$

was established by two independent criteria: (a) by comparing the relative binding of oxLDL compared to nLDL and (b) the competitive inhibition of oLAb binding to the solid phase by soluble oxLDL. The broad range of inhibition obtained (17-100\%) seems logical, as in vitro prepared oxLDL differs in its epitope spectrum from in vivo generated oxLDL. Therefore, the degree of inhibition is not predictable and depends on how much the artificial oxLDL corresponds to the epitope pattern displayed on in vivo oxidized LDL eliciting the antibody response. Even minor modifications render LDL immunogenic [35]. Copper-catalysed in vitro LDL oxidation, however, represents a major LDL modification. As shown by Preobrazhensky et al. [36] binding of monoclonal antibodies to LDL depends on LDL oxidation time. Thus, antibody binding to LDL during in vitro LDL oxidation can increase, decrease or remain unchanged. Similar mechanisms could apply to polyclonal autoantibodies found in IDDM sera. Patientspecific differences in oxLDL antibody affinity may also be responsible for differences in the inhibitory capacity of in vitro produced oxLDL. However, apart from the fact that they contain MDA-groups, the exact nature of the epitopes generated by oxidative modification of LDL is unknown and epitopes may be distributed among multiple apo B fragments.

Contrary to what might be expected, we observed a negative correlation between the oLAb ratio and metabolic control. An inverse relationship between $\mathrm{HbA}_{1}$ and oLAb in IDDM patients was also found by Korpinen et al. [30]. In addition, in our study patients with longstanding disease as well as microvascular complications presented with lower antibody titres. According to these results, oLAb therefore do not seem to be of value in predicting the progression of an already established atherosclerosis in patients with IDDM, as long as only free oLAb are measured. However, our detection of oLAb in IDDM patients without clinical evidence of atherosclerosis, the ob-

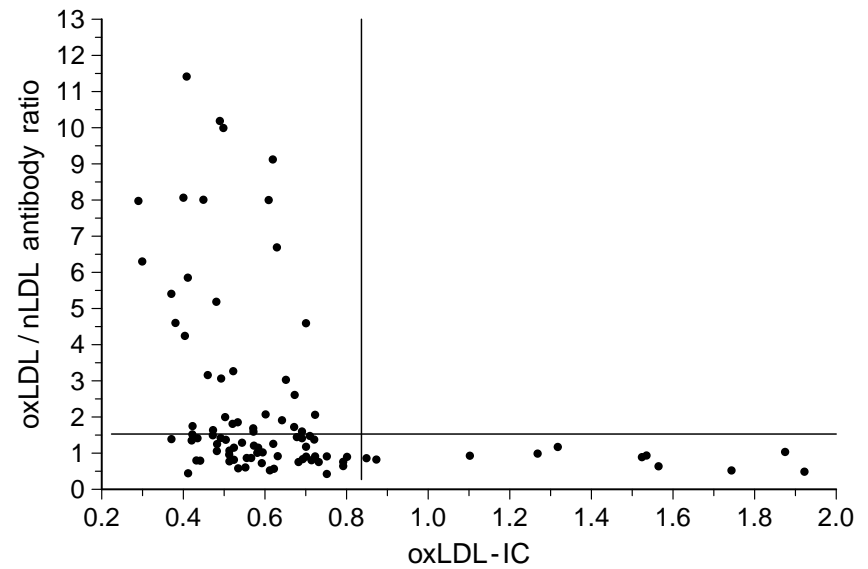

Fig. 3. Correlation of oxLDL/nLDL antibody ratio with oxLDL-IC-titers (OD) in patients with IDDM $(n=94)$; $r=-0.31, p<0.0001$. The horizontal line represents the cut-off limit for oLAb positive vs negative patients (oxLDL/nLDL ratio: 1.5), the vertical line represents the threshold for oxLDLIC positivity (OD: 0.82), i.e. in the upper left quadrant each dot represents a patient with positive oLAb titre in the absence of immune complexes, the lower left quadrant shows patients without immune complexes and without free antibodies, the lower right quadrant represents patients with immune complexes in the absence of oLAb. There are no patients with both free and immune complex bound antibodies to oxLDL (right upper quadrant)

servation of Bellomo et al. [14] of high oLAb titres even in NIDDM patients without clinical evidence of vascular lesions as well as the finding by Virella et al. [12] of oLAb in asymptomatic young adults indicate that the immune response to modified LDL can precede clinical evidence of atherosclerosis.

The reasons for an inverse correlation between $\mathrm{oLAb}$ and the severity of the disease could be (a) formation of circulating immune complexes "hiding" free oLAb, supported by our finding of an inverse relationship between free oLAb and oxLDL-IC and (b) binding of oLAb to epitopes on oxLDL exposed by atherosclerotic lesions and oxidized cell membranes. Only in IDDM patients with poor metabolic control has increased susceptibility of LDL to oxidation been described [26, 37]. Accordingly, we were able to demonstrate circulating oxLDL-IC predominantly in the less well controlled patient group, using a new method for the detection of such IC. It is therefore reasonable to assume that in patients with poorly controlled diabetes free oLAb form more readily and are masked partly in immune complexes with circulating oxLDL and therefore cannot be detected by our ELISA for oLAb. This suggestion is bolstered by our finding of an inverse correlation between oLAb titres and immune complex levels, as shown in Figure 3 , indicating that with increasing presence of immune complexes plasma concentration of free oLAb subsides. The transient reduction of oLAb in patients with acute myocardial infarction has also been ex- 
plained by IC formation [38]. In the large majority of patients these oxLDL-IC could activate complement via the classical pathway and interacted with $\mathrm{C} 1 \mathrm{q}$; i.e. were found in patients also showing IC in the classical IC assay using C1q-coated solid phase. Although in vivo such complexes are probably bound to a large extent by erythrocytes and ingested via $\mathrm{F}_{\mathrm{c}}$-gamma receptors by monocytes/macrophages [39], free LDLIC have been detected in the circulation of patients with manifestations of atherosclerosis [40, 41].

In IDDM, the selective destruction of pancreatic beta cells is associated with both cellular and humoral autoimmunity as a function of HLA class II genes. Islet cell antibodies, insulin autoantibodies and antiGAD 65 antibodies have been documented at or before clinical diagnosis and may predict IDDM. The lack of a significant correlation between oLAb and anti-GAD, found in our population, could be explained by the different nature of the respective antigens: Thus, GAD is a major target antigen in IDDM, while oxLDL is a "bystander" antigen indicating increased oxidative stress characteristic of diabetes and leading to accelerated atherosclerosis. Furthermore, even antibodies to the different islet autoantigens appear sequentially rather than simultaneously. The evaluation of the role of oxLDL as autoantigen or oLAb as autoantibodies in this sequence of events will therefore require follow-up over a number of years after the first evidence of islet autoimmunity. Although for oLAb data on HLA association and time course of manifestation in free or IC-bound form during progression of the disease are lacking, the general propensity to react strongly with certain autoantigens seen in patients with IDDM suggests that oLAb may be formed at an earlier stage, in higher quantities and with a higher affinity, and thus a higher tendency to form IC, than in NIDDM. This could explain why the inverse relationship between severity of disease and presence of circulating oLAb was not found in patients with NIDDM [14].

Acknowledgements. We gratefully acknowledge Ms. C. Zangerle for laboratory and technical assistance. This work was supported by the Austrian Research Funds Project No. MED10918 and by the Nationalbank Jubiläumsfonds No. 5690 NB.

\section{References}

1. Kannel WB, McGee DL (1979) Diabetes and cardiovascular disease. The Framingham Study. J Am Med Assoc 241: 2035-2038

2. Schneider DJ, Nordt TK, Sobel BE (1993) Attenuated fibrinolysis and accelerated atherogenesis in type II diabetic patients. Diabetes 42:1-7

3. Stout RW (1990) Insulin and atheroma: 20 year perspective. Diabetes Care 13:631-655

4. Brownlee M, Cerami A, Vlassara H (1988) Advanced glycosylation endproducts in tissue and the biochemical basis of diabetic complications. N Engl J Med 318:1315-1321
5. Lopes-Virella MF, Lopes-Virella G (1996) Cytokines, modified lipoproteins, and atherosclerosis in diabetes. Diabetes 45 [Suppl 3]:S40-S44

6. Lyons TJ (1991) Oxidized low density lipoproteins: a role in the pathogenesis of atherosclerosis in diabetes? Diabet Med 8:411-419

7. Palinski W, Rosenfeld ME, Yla-Herttuala S et al. (1989) Low-density lipoprotein undergoes oxidative modification in vivo. Proc Natl Acad Sci USA 86:1372-1376

8. Ross R (1993) The pathogenesis of atherosclerosis: a perspective for the 1990s. Nature 362:801-809

9. Witztum JL, Steinberg D (1991) Role of oxidised low density lipoprotein in atherogenesis. J Clin Invest 88:17851792

10. Esterbauer H, Striegl G, Puhl H, Rotheneder M (1989) Continuous monitoring of in vitro oxidation of human low density lipoprotein. Free Radical Res Commun 6:67-75

11. Cazzolato G, Avogaro P, Bittolo-Bon G (1991) Characterization of a more electronegatively charged LDL subfraction by ion exchange HPLC. Free Radical Biol Med 11:247-253

12. Virella G, Virella I, Leman RB, Pryor MB, Lopes-Virella MF (1993) Antioxidized low density lipoprotein antibodies in patients with coronary disease and normal healthy volunteers. Int J Clin Lab Res 23:95-101

13. Maggi E, Marchesi E, Ravetta V, Falaschi F, Finardi G, Bellomo G (1993) Low-density lipoprotein oxidation in essential hypertension. J Hypertens 11: 1103-1111

14. Bellomo G, Maggi E, Poli M, Agosta FG, Bollati P, Finardi G (1995) Autoantibodies against oxidatively modified low-density lipoproteins in NIDDM. Diabetes 44:60-66

15. Salonen JT, Ylä-Herttuala S, Yamamoto R et al. (1992) Autoantibodies against oxidized LDL and progression of carotid atherosclerosis. Lancet 339:883-887

16. Maggi E, Bellazzi R, Falaschi F et al. (1994) Enhanced LDL oxidation in uremic patients: An additional mechanism for accelerated atherosclerosis ? Kidney Int 45:876883

17. Ylä-Herttuala S, Palinski W, Rosenfeld ME et al. (1989) Evidence for the presence of oxidatively modified LDL in atherosclerotic lesions of rabbit and man. J Clin Invest 84:1086-1095

18. Gisinger C, Virella GT, Lopes-Virella MF (1991) Erythrocyte-bound LDL immune complexes lead to CE accumulation in human macrophages. Clin Immunol Immunopathol 59:37-51

19. Jäättelä M (1991) Biologic activities and mechanisms of action of tumor necrosis factor $\alpha /$ cachectin. Lab Invest 64:724-742

20. Dinarello CA (1991) Interleukin-1 and interleukin-1 antagonism. Blood 77:1627-1652

21. Hunt JV, Smith CCT, Wolff SP (1990) Auto-oxidative glycosylation and possible involvement of peroxides and free radicals in LDL modification by glucose. Diabetes 39: $1420-1424$

22. Jennings PE, Jones AF, Flurkowski CM, Lunec J, Barnett AH (1987) Increased diene conjugates in diabetic subjects with microangiopathy. Diabetic Med 4:452-456

23. Bucala R, Makita Z, Koschinsky T, Cerami A, Vlassara H (1993) Lipid advanced glycosylation: pathway for lipid oxidation in vivo. Proc Natl Acad Sci USA 90:6434-6438

24. Schleicher E, Deufel T, Wieland OH (1981) Non-enzymatic glycosylation of human serum lipoproteins. FEBS Lett 129:1-4

25. Curtiss LK, Witztum JL (1985) Plasma apo-lipoproteins A-I, A-II, B, C-I and E are glucosylated in hyperglycemic diabetic subjects. Diabetes 34:452-461 
26. Lyons TJ, Patrick JS, Baynes JW, Colwell JA, Lopes-Virella MF (1986) Glycation of low density lipoprotein in patients with type 1 diabetes: correlations with other parameters of glycaemic control. Diabetologia 29:685-689

27. Tsai EC, Hirsch IB, Brunzell JD, Chait A (1994) Reduced plasma peroxyl radical trapping capacity and increased susceptibility of LDL to oxidation in poorly controlled IDDM. Diabetes 43:1010-1014

28. Rabini RA, Fumelli P, Galassi R et al. (1994) Increased susceptibility to lipid oxidation of low-density lipoproteins and erythrocyte membranes from diabetic patients. Metabolism 43:1470-1474

29. Haffner MS, Agil A, Mykkänen L, Stern MP, Jialal I (1995) Plasma oxidizability in subjects with normal glucose tolerance, impaired glucose tolerance, and NIDDM. Diabetes Care 18:646-653

30. Korpinen E, Groop PH, Akerblom HK, Vaarala O (1997) Immune response to glycated and oxidized LDL in IDDM patients with and without renal disease. Diabetes Care 20:1168-1171

31. National Diabetes Data Group (1979) Classification of diabetes mellitus and other categories of glucose intolerance. Diabetes 28:1039

32. Dimitriadis E, Griffin M, Owens D, Johnson A, Collins P, Tomkin GH (1995) Oxidation of low-density lipoprotein in NIDDM: its relationship to fatty acid composition. Diabetologia 38:1300-1306

33. Menzel EJ, Sobal G, Staudinger A (1997) The role of oxidative stress in the long-term glycation of LDL. BioFactors 6:111-124
34. Maggi E, Perani G, Finardi G, Franceschi C, Bellomo G (1993) LDL oxidation in aging. In: Rice Evans C, Corongiu F (eds) Free radicals and antioxidants in nutrition. Richelieu Press, Paris, pp 427-437

35. Berliner JA, Territo MC, Sevanian A (1990) Minimally modified low density lipoprotein stimulates monocyte endothelial interactions. J Clin Invest 85:1260-1266

36. Preobrazhensky S, Trakht I, Chestkov V, Wentz M (1995) Monoclonal antibody-based immunoassay for evaluation of lipoprotein oxidation. Anal Biochem 227:225-234

37. Jenkins AJ, Klein RL, Chassereau CN, Hermayer KL, Lopes-Virella MF (1996) LDL from patients with well controlled IDDM is not more susceptible to in vitro oxidation. Diabetes 45:762-767

38. Schumacher M, Eber B, Tatzber F et al. (1995) Transient reduction of autoantibodies against oxidised LDL in patients with acute myocardial infarction. Free Radic Biol Med 18:1087-1091

39. Virella G, Munoz JF, Galbrath GMP et al. (1995) Activation of human monocyte-derived macrophages by immune complexes containing low-density lipoprotein. Clin Immunol Immunopathol 75:179-189

40. Tertov VV, Orkhov AN, Kacharava AG, Sobenin IA, Perova NV, Smirnov VN (1990) Low density lipoprotein containing circulating immune complexes and coronary atherosclerosis. Exp Mol Pathol 52:300-308

41. Szondy E, Lengyel E, Mezey Z, Füst G, Gerö S (1985) Occurrence of anti-low density lipoprotein antibodies and circulating immune complexes in aged subjects. Mech Aging Dev 29:117-123 